\title{
Pengaruh Pemahaman Panggilan Guru Kristen terhadap Pemberitaan Injil
}

\author{
Justin Niaga Siman Juntak \\ Fakultas Teologi Universitas Kristen Surakarta \\ justinsimanjuntak@gmail.com
}

\begin{tabular}{l} 
Article History \\
Received: \\
7 April 2019 \\
Revised: \\
8 Mei 2019 \\
Published: \\
31 Mei 2019 \\
\hline \\
Keywords \\
(Kata kunci): \\
Christian teacher; \\
the calling; \\
preaching gospel; \\
the calling of teacher; \\
guru Kristen; \\
panggilan; \\
panggilan guru; \\
pemberitaan Injil \\
\end{tabular}

\begin{abstract}
Gospel preaching is a very important task, including for Christian teachers who teach in schools. The entry of non-Christian teachers in YPK Pelita Pengharapan schools, moreover the subject of Islamic Education in two YPK Pelita Pengharapan Christian schools and being a teacher as a stepping stone to becoming civil servants indicates a weak preaching process in YPK Pelita Christian School Hope. The study was conducted to obtain empirical evidence about the influence of the understanding of Christian teacher's call to preaching the Gospel The Javanese Christian Church teachers in the Pelita Pengharapan Christian Education Foundation Research School were conducted in nine schools of the Pelita Pengharapan Christian Education Foundation spread in three subdistricts namely Patimuan, Sidareja and Gandrungmangu. The data analysis method used is a simple regression analysis of 51 respondents. The results showed that the understanding of the Christian teacher's call had a positive and significant effect on the preaching of the Gospel of the Javanese Christian Church Teachers in the schools of the Pelita Pengharapan Christian Education Foundation, Cilacap Regency.
\end{abstract}

\begin{abstract}
Abstrak
Pemberitaan Injil merupakan tugas yang sangat penting, termasuk bagi para guru Agama Kristen yang mengajar di sekolah. Masuknya guru-guru non Kristen di sekolah-sekolah YPK Pelita Pengharapan, terlebih lagi mata pelajaran Pendidikan Agama Islam di dua sekolah Kristen YPK Pelita Pengharapan dan menjadi guru sebagai batu loncatan untuk menjadi Pegawai Negeri Sipil mengindikasikan proses pemberitaan Injil yang lemah di sekolah Kristen YPK Pelita Pengharapan. Penelitian dilakukan untuk memperoleh bukti empiris tentang pengaruh pemahaman tentang panggilan guru Kristen terhadap Pemberitaan Injil Guru-guru Gereja Kristen Jawa di sekolah-sekolah Yayasan Pendidikan Kristen Pelita Pengharapan Penelitian ini dilakukan di sembilan sekolah Yayasan Pendidikan Kristen Pelita Pengharapan yang tersebar di tiga kecamatan yaitu Patimuan, Sidareja dan Gandrungmangu. Metode analisis data yang digunakan adalah analisis regresi sederhana terhadap 51 responden. Hasil penelitian menunjukkan bahwa pemahaman panggilan guru Kristen berpengaruh positif dan signifikan terhadap pemberitaan Injil Guru-guru Gereja Kristen Jawa di sekolah-sekolah Yayasan Pendidikan Kristen Pelita Pengharapan Kabupaten Cilacap.
\end{abstract}




\section{Pendahuluan}

Sembilan orang dari kalangan terbawah masyarakat Jawa dengan profesi buruh miskin, tukang membatik yang bekerja pada Ny. Van Oostrom Phillips di Banyumas, nekad berjalan kaki dalam rombongan kecil menerabas desa-desa dan pegunungan menuju Semarang, sejauh sekitar $300 \mathrm{Km}$. Suatu perjalanan panjang untuk sekedar mendapatkan tanda baptis dari Zendeling NZG W. Hoezoo pada 10 Oktober $1858^{1}$, semenjak itu pula orang-orang Kristen Jawa mulai berkembang bertambah banyak. Dalam perkembangannya mereka berkumpul untuk berhimpun yang kemudian menjadi gereja lokal di 17 tempat yang kemudian bersidang bersama-sama pada tanggal 17-18 Februari 1931 dan menamakan diri Pesamoewan Gereformeede Djawi Tengah yang kemudian dikenal sebagai Gereja Kristen Jawa. ${ }^{2}$

Tujuan Pemberitaan Injil Gereja Kristen Jawa sesuai pasal 35 : Tujuan Pemberitaan Injil Penyelamatan Allah adalah demi keselamatan manusia. ${ }^{3}$ Sebagai wujud pelaksanaan dari kesaksian penyelamatan Allah untuk pemberitaan Injil maka segala upaya harus dilakukan oleh gereja untuk memberitakan keselamatan Allah yang berpusat kepada Tuhan Yesus Kristus kepada semua orang.

Berangkat dari tugas itulah banyak lembaga-lembaga Kristen didirikan sebagai upaya gereja untuk menunjang pelayanan pemberitaan Injil, termasuk di dalamnya sekolah-sekolah Kristen. Demikian pula keberadaan Yayasan Pendidikan Kristen (YPK) Pelita Pengharapan Kabupaten Cilacap yang didirikan sejak tahun 2008 merupakan pemekaran dari Yayasan Pendidikan Kristen (YPK) Kabupaten Cilacap - suatu yayasan yang didirikan oleh Gereja-gereja Kristen Jawa yang ada di Klasis Citanduy sebagai pemilik yayasan melalui wakil-wakilnya sebagai dewan pembina sebagai akibat dari pemekaran wilayah pelayanan Klasis Banyumas Selatan dan Citanduy. ${ }^{4}$

YPK Pelita Pengharapan membawahi sembilan sekolah yang telah ada sebelumnya dan tersebar di tiga kecamatan yang ada di Kabupaten Cilacap yaitu : Sidareja, Gandrungmangu dan Patimuan. Sekolah Kristen yang ada di bawah YPK Pelita Pengharapan Kabupaten Cilacap (dulunya di bawah YPK Kabupaten Cilacap) pada awalnya didirikan dengan maksud sebagai sarana pemberitaan Injil guna memperkuat keberadaan gereja di lingkungannya. ${ }^{5}$ Dengan adanya sekolah Kristen maka peran Pendidikan Agama Kristen menjadi sentral dan menghidupi setiap aspek dalam proses pembelajaran di sekolah, ${ }^{6}$ sehingga minimal lulusan dari sekolah Kristen diwarnai oleh pendidikan yang bernilai Kristiani atau bahkan ada yang menjadi percaya kepada Tuhan Yesus Kristus karena proses pendidikan di sekolah Kristen tersebut.

\footnotetext{
${ }^{1}$ Sinode GKJ, Sejarah Singkat Sinode GKJ (Salatiga: Sinode GKJ, 2013), 1.

${ }^{2}$ Ibid., 3.

${ }^{3}$ Ibid., 17.

${ }^{4}$ Dwi Eko Abriwijono, "Studi Evaluasi Motivasi Mengajar Guru di Sekolah Kristen YPK Pelita Pengharapan", Tesis (Semarang: STBI, 2010), 9-10.

${ }^{5}$ Dwi Eko Abriwijono, Sejarah Klasis Citanduy (Sidareja: Klasis Citanduy, 2007), 12.

${ }^{6}$ Sularso Sopater, "Memantapkan Pelaksanaan Identitas dan Ciri Khas Pendidikan Kristen Secara Kontinyu dan Konsisten" dalam buku Identitas dan Ciri Khas Pendidikan Kristen di Indonesia (Jakarta: BPK Gunung Mulia, 2006), 19.
} 
Dengan masuknya guru-guru bidang studi yang bukan Kristen dan diangkat menjadi guru di sekolah Kristen Yayasan Pendidikan Kristen Pelita Pengharapan Kabupaten Cilacap untuk mengisi kekosongan tenaga pendidik berbenturan dengan spirit yang dimiliki sejak awal, sehingga muncul keraguan dan kegelisahan Gerejagereja Kristen Jawa di Klasis Citanduy berkenaan dengan sekolah Kristen ini apakah masih menjadi sarana Pemberitaan Injil bagi gereja. Ditambah lagi dengan adanya Undang-undang Republik Indonesia nomor 20 tahun 2003 tentang Sistem Pendidikan Nasional pasal 12 ayat 1a yang berbunyi setiap peserta didik harus diajar sesuai dengan ajaran agama yang dianutnya, ${ }^{7}$ dipakai oleh berbagai pihak melalui Kementrian Agama untuk mengirimkan tenaga guru Pendidikan Agama Islam di sekolah-sekolah Kristen. Alhasil sekolah tersebut di bawah tekanan pihak Kementrian Agama merasa tidak berdaya dan akhirnya menerima guru Pendidikan Agama Islam dengan harapan semakin banyak calon peserta didik yang akan masuk di tahun-tahun ajaran baru tanpa rasa kuatir orang tua bahwa anaknya akan diajarkan agama Kristen, guna mempertahankan keberadaan sekolah.

Hal ini menjadi indikasi bahwa proses pemberitaan Injil mendapat tekanan dan bisa menjadi lemah di sekolah Kristen YPK Pelita Pengharapan. Kegelisahan tentang pentingnya pemberitaan Injil ini tetap nampak dalam persidangan yang ke-11 Gerejagereja Kristen Jawa Klasis Citanduy yang menandaskan pengharapannya agar sekolahsekolah Kristen di YPK Pelita Pengharapan Kabupaten Cilacap menjadi lembaga yang strategis dan efektif dalam rangka pemberitaan Injil. ${ }^{8}$

Kondisi sekolah Kristen di atas sudah sulit dirubah, tetapi apakah tugas pemberitaan Injil ini akan menjadi berhenti? Tentunya tidak, karena masih ada celah pemberitaan Injil yang masih dapat dilakukan yaitu melalui guru-guru Kristen di sekolah yang ada di sekolah-sekolah Kristen YPK Pelita Pengharapan Kabupaten Cilacap. Seorang guru pasti mempunyai pengaruh kepada para nara didik dan lingkungannya, termasuk guru Kristen menjadi ujung tombak sebagai pemberitaan Injil di sekolah-sekolah Kristen YPK Pelita Pengharapan Kabupaten Cilacap. Penelitian ini dilakukan untuk memperoleh bukti tentang seberapa besar pengaruh pemahaman tentang Panggilan Guru Kristen terhadap Pemberitaan Injil guru-guru Gereja Kristen Jawa di Sekolah-sekolah Yayasan Pendidikan Kristen Pelita Pengharapan Kabupaten Cilacap.

\section{Hakikat Pendidikan Kristen}

Menurut Daniel Nuhamara, ada elemen-elemen inti yang dapat menjelaskan hakikat Pendidikan Kristen yaitu suatu usaha pendidikan yang khusus yakni dalam dimensi religius manusia dimana menunjuk kepada persekutuan iman yang melakukan tugas pendidikan agamawi, yakni persekutuan iman Kristen. ${ }^{9}$ Senada dengan

\footnotetext{
${ }^{7}$ Undang-undang Republik Indonesia Nomor 20 Tahun 2003 tentang Sistem Pendidikan Nasional.

${ }^{8}$ Akta Sidang Klasis ke-9 GKJ Klasis Citanduy artikel 33.

${ }^{9}$ Daniel Nuhamara, Pembimbing Pendidikan Agama Kristen (Bandung: Jurnal Info Media, 2007), $25-26$.
} 
Nuhamara, Nainggolan mengatakan bahwa pendidikan Kristen haruslah memiliki tujuan yang mengarah pada transformasi baik pengetahuan maupun dalam transformasi iman, sehingga tujuan tertingginya adalah membawa siswa mengalami perjumpaan dengan Kristus. $^{10}$

\section{Pendidikan Kristen di Sekolah}

Menurut Posumah, hakikat pendidikan Kristen adalah tugas panggilan gereja untuk menumbuhkan dan mengembangkan kemampuan peserta didik agar dengan pertolongan Roh Kudus dapat memahami dan menghayati Kasih Allah dalam Yesus Kristus yang dinyatakan dalam kehidupan sehari-hari, terhadap sesama dan lingkungan hidupnya, ${ }^{11}$ sehingga penanggungjawab Pendidikan Agama Kristen adalah gereja dan bukannya badan lain. ${ }^{12}$ Dengan pengertian tersebut maka gereja mempunyai kewajiban untuk mengawal secara serius Pendidikan Kristen baik di sekolah non keagamaan baik negeri ataupun swasta, apalagi di sekolah Kristen.

Dengan demikian dapat dikatakan bahwa pendidikan Kristen di sekolah merupakan tanggung jawab bersama yang dilakukan secara sadar dan tidak dapat dilepaskan dari peran aktif gereja sebagai komunitas masyarakat yang merupakan pendiri dan pemilik dari sekolah serta guru agar peserta didik dapat dibina menuju tujuan yang telah disepakati bersama dalam komunitasnya. ${ }^{13}$

\section{Panggilan Guru Kristen}

Guru Kristen di sini lebih ditekankan kepada guru yang percaya kepada Yesus Kristus, yang mengenal akan pribadi Yesus serta yang memiliki pribadi yang meneladani Yesus sebagai guru besarnya. ${ }^{14}$ Nainggolan juga mengungkapkan beberapa pokok berkaitan dengan panggilan guru Kristen yaitu : meneladani Yesus Kristus, mengasihi para murid, bertumbuh di dalam Kritus, bergantung pada kuasa Roh Kudus, memberikan sentuhan Firman Tuhan, membawa kepada perjumpaan dengan Kristus.

\section{Motivasi Pemberitaan Injil}

Iswara Rintis Purwantara mengutip pernyataan Werneck bahwa pelaku-pelaku pemberitaan Injil adalah orang orang Kristen sendiri ${ }^{15}$, sehingga mau tidak mau orang Kristen harus mempunyai motivasi yang benar untuk memberitakan Injil. Berkenaan dengan hal itulah maka penginjilan merupakan juga tugas panggilan gereja seperti yang

\footnotetext{
${ }^{10}$ John M. Nainggolan, Menjadi Guru Agama Kristen; Suatu Upaya Peningkatan Mutu dan Kualitas Profesi Keguruan (Bandung: Generasi Info Media, 2007), 11.

${ }^{11}$ Jedida T. Posumah-Santosa, "Pendidikan Agama Kristen di Sekolah: Suatu Bidang Studi atau Asuhan Iman Kristen?” dalam Ajarlah Mereka Melakukan (Jakarta: BPK Gunung Mulia, 1998), 157.

${ }^{12}$ Ibid., 160.

${ }^{13}$ Thomas Lickona, Pendidikan Karakter, Panduan Lengkap Mendidik Siswa menjadi Pintar dan Baik (Bandung: Nusamedia, 2013), 536-537. Hal ini senada seperti yang diungkapkan oleh Karen B. Tye dalam bukunya Basics of Christian Education hal, 9-10, bahwa pendidikan Kristen menjadi tugas bersama masyarakat Kristen secara menyeluruh untuk memperkenalkan Allah dan memahamkan prinsip kekristenan.

${ }^{14}$ Nainggolan, Menjadi Guru Agama Kristen, 23.

${ }^{15}$ Iswara Rintis Purwantara, Prapenginjilan (Yogyakarta:Penerbit Andi, 2012), 108.
} 
diungkapkan oleh Lukas Eko Sukoco, bahwa sebagai umat milik Allah, gereja dilibatkan dalam karya penyelamatan Allah. Maka tugas dan panggilan gereja adalah berfungsi dalam karya penyelamatan Allah di dunia. ${ }^{16}$

\section{Tugas Panggilan Gereja Kristen Jawa}

Ada dua tugas panggilan Gereja Kristen Jawa yaitu Pemberitaan Injil (bersaksi) dan pemeliharaan Iman. Tugas panggilan gereja adalah bekerja memberitakan Injil sambil terus berusaha memelihara dan mengaktualisasikan imannya. ${ }^{17}$ Tugas panggilan untuk bekerja memberitakan Injil tersebut mengandung arti lebih dari sekedar upaya menyampaikan berita Injil kepada orang yang belum mengenal Injil, melainkan juga melakukan perbuatan yang mengekspresikan tindakan penyelamatan serta pemeliharaan Allah sehingga tanda-tanda kehadiran Kerajaan Allah dapat dilihat dan dirasakan oleh lingkungan di sekitarnya.

Teolog Belanda Arie de Kuiper yang dikutip oleh Andreas Untung Wiyono menjelaskan bahwa ketiga tugas gereja tersebut sebenarnya merupakan suatu kesatuan yang utuh dari tugas apostolik yang menandai kehadiran Kerajaan Allah, sebagaimana tercermin dari ketiga jenis atau motif Pemberitaan Injil yaitu :

a. Pemberitaan Injil Pietis : penyegaran jiwa orang percaya, sehingga jiwa perlu untuk selalu mendapat pemberitaan Injil. Kerajaan Allah berarti keseluruhan orang-orang yang bertobat dan selamat (aspek koinonia).

b. Pemberitaan Injil Gerejani : dari gereja kepada gereja. Tujuan utamanya adalah ditanamnya dan diperkembangkannya gereja (aspek marturia).

c. Pemberitaan Injil Filantropis: motifnya bersifat sosial-etis. Tujuannya adalah untuk meringankan penderitaan orang-orang yang menderita (aspek diakonia). ${ }^{18}$

Dari keterangan di atas dapat ditarik kesimpulan bahwa visi gereja GKJ yang dikembangkan selama ini adalah : hadirnya Kerajaan Allah. Sedangkan misi dan tujuannya adalah mendatangkan syalom (damai sejahtera, keselamatan) melalui pemberitaan injil. ${ }^{19}$ Dengan kata lain bahwa pola pelayanan yang dibangun haruslah mendukung berbabagi upaya mewujudkan mimpi gereja sebagai Kerajaan Allah yang hadir di tengah dunia.

\section{Pemberitaan Injil di GKJ}

Pemberitaan Injil bukan hanya sekedar perbuatan baik dan benar, namun lebih dari pada itu, pemberitaan Injil merupakan persekutuan dan persahabatan dengan Allah yang hidup. ${ }^{20}$ Demikian pula seperti diungkapkan oleh E.G. Homrighausen dan I.H. Enklaar

\footnotetext{
${ }^{16}$ Lukas Eko Sukoco, Panduan Pelayanan Gerejawi (Yogyakarta: Taman Pustaka Kristen, 2006),

${ }^{17}$ Sinode GKJ, Pokok-pokok Ajaran GKJ, Edisi 2005 (Salatiga: Sinode GKJ, 2006), viii.

${ }^{18}$ Andreas Untung Wiyono, Eklesiologi GKJ (Salatiga: Sinode GKJ, 2013), 19-20.

${ }^{19}$ Ibid.

${ }^{20}$ Stephen Hawthorne, Perspektif penginjilan Sedunia (tp:tt), 1.
} 24. 
bahwa pemberitaan Injil sangat berkaitan erat dengan Pendidikan. ${ }^{21}$ Ditinjau dari sudut pandang budaya, GKJ hidup di tengah budaya Jawa. Maka budaya yang berkembang di tengah masyarakat sehubungan dengan visi, misi dan tujuan gereja lebih banyak dipengaruhi oleh pandangan umum tentang watak ekspansif agama-agama Samawi (Yahudi, Kristen dan Islam). Oleh karena itu kehadiran gereja seringkali dipahami dengan penuh curiga sebagai upaya kristenisasi. Beberapa gereja yang berada di tengahtengah komunitas muslim khususnya pada umumnya merasakan hal ini.

\section{Pemberitaan Injil Aspek Koinonia}

Aspek ini menekankan pada pemahaman tentang pemeliharaan iman antara warga jemaat. Membangun hubungan yang erat baik dalam relasi sosial antara warga jemaat dan relasi dengan Tuhan Yesus sebagai Raja Gereja. Gereja sebagai Koinonia adalah tubuh Kristus. Di dalam tubuh Kristus, semua orang menjadi satu, dan satu di dalam semua oleh Kristus (1 Kor.12:26).

Jadi, yang dimaksud dengan Pemberitaan Injil Koinonia adalah pertama, persekutuan dalam ibadah minggu dan sakramen. Di mana dua hal tersebut menjadi pusat dari liturgi pemeliharaan iman kehidupan umat Kristen yang percaya kepada Yesus Kristus sebagai Tuhan dan Juruselamat secara pribadi. Kedua, terlibat aktif di dalam pelayanan gerejawi, hal ini menjadi reaksi yang konkrit dari iman percaya tersebut di atas sebagai bentuk ungkapan syukur yang dinyatakan dalam pelayanan gerejawi. Ketiga adalah menjalin hubungan dengan warga seiman. Relasi yang baik antar warga seiman akan semakin menguatkan persekutuan, menegur dengan kasih dan menghindarkan dari hal-hal menyebabkan orang berpaling kepada Kristus.

\section{Pemberitaan Injil Aspek Marturia}

Seperti dipahami di atas berkenaan dengan pentingnya bertambahnya jumlah warga gereja sebagai buah dari pemberitaan Injil, maka praktik pemberitaan Injil menurut Tomatala, dihubungkan dengan konsep tubuh yang dikenakan kepada gereja Yesus Kristus. Body Evangelism - Body Life Concept yang dituangkan dalam strategi 3P (Presence, Proclamation \& Persuasion). ${ }^{22}$ Presence, yaitu pemberitaan Injil melalui kehadiran di tengah-tengah masyarakat. Proclamation, menjelaskan tentang tanggung jawab memberitakan isi Injil (1 Kor. 15:1-4) dengan jelas dan tegas tanpa kompromi, tetapi penuh hikmat. Persuation, menekankan cara sikap atau cara menyampaikan Injil yang berwibawa dan meyakinkan orang tentang kebenaran Injil Yesus Kristus dan menuntut keputusan untuk percaya bagi Kristus. Hal ini penting untuk memastikan karunia Allah dalam kehidupan setiap orang (Yoh. 3:16; 1:12; 1 Yoh. 5:13). Di bawah ini akan dipaparkan tentang tiga Pemberitaan Injil aspek Marturia.

${ }^{21}$ E.G. Homrighausen dan I.H. Enklaar, Pendidikan Agama Kristen (Jakarta: BPK Gunung Mulia, 1991), 197.

${ }^{22}$ Yakop Tomatala, Penginjilan Masa Kini (Malang: Gandung Mas, 2004), 47. 


\section{Pemberitaan Injil Presensi}

Bentuk presensi ini menunjuk kepada tanggungjawab gereja secara sadar yang diwujudkan dengan tindakan sosial melalui "kehadiran terencana" sebagai suatu kesaksian dalam masyarakat. Menurut Wagner, penginjilan presensi adalah terutama sekali seseorang harus membentuk hubungan yang baik dengan orang-orang yang tidak seiman, dengan oleh menolong orang untuk memenuhi kebutuhan-kebutuhan mereka. Jadi tujuannya adalah untuk melakukan perbuatan baik, yang kadang-kadang dilakukan dalam nama Yesus, tetapi kadang pula tidak. Para penganut pendapat ini tidak keberatan disebut sebagai "saksi-saksi tanpa identitas". 23

Robert Cook dalam bukunya yang berjudul Setelah Aku Percaya, mengemukakan bahwa maksud dari pemberitaan Injil lebih merupakan suatu demonstrasi (hidup Kristen) Injil dari pada sebuah proklamasi (pemberitaan Injil verbal) Injil. $^{24}$

\section{Pemberitaan Injil Proklamasi}

Pemberitaan Injil proklamasi menyatakan bahwa pemberitaan Injil adalah bukan sekedar melakukan perbuatan baik. Salah satu faktor adalah pengungkapan secara lisan berita Injil tentang Yesus Kristus. Pemberitaan Injil adalah pemberitaan kabar baik tentang Yesus dengan cara yang sedemikian rupa sehingga orang-orang akan mendengarkan dan memahami kabar baik itu. Setelah hal itu dilakukan dan orang-orang telah mendengar dan memahami Injil yang diberitakan itu, maka mereka telah dianggap diinjili. Sebagian akan percaya Injil dan sebagian akan menolaknya, tetapi apapun keputusan mereka, mereka telah mendengar berita Injil.

\section{Pemberitaan Injil Persuasi}

Tomatala menjelaskan bahwa penginjilan persuasi adalah tindakan peyakinan. ${ }^{25}$ Tindakan ini diwujudkan dengan upaya memberi tantangan yang persuasi agar setiap pendengar Injil dapat 'menyambut Yesus Kristus' sebagai Tuhan dan Juruselamat secara pribadi. Demikian pula penyelidikan mengenai pelayanan Paulus di Athena, dapat dilihat bahwa Paulus menggunakan metode persuasi (membujuk dan meyakinkan orang) ketika memberitakan Injil.

\section{Pemberitaan Injil Aspek Diakonia}

Pemberitaan dan kesaksian itu tidaklah selalu dilaksanakan dengan kata-kata tetapi juga dengan perbuatan atau pelayanan diakonia. Perlu diingat bahwa ada kalanya suara perbuatan lebih nyaring gaungnya dari pada perkataan. Dengan tindakan maka Injil juga dapat diberitakan dan didengar oleh orang-orang tuli (Luk. 22:26-30).

Pelayanan diakonia sering dipahami hanya sebatas konsep caritas, membantu para janda, yatim piatu, fakir miskin demi kesejahteraannya (KPR 6 :22 dan Mat. 25:42-44). Sebenarnya, gereja dalam pelayanan diakonia harus mencakup : pelayanan diakonia

\footnotetext{
${ }^{23}$ C. Peter Wagner, Strategi Perkembangan Gereja (Malang: Gandum Mas, th), 104.

${ }^{24}$ Robert Cook, Setelah Aku Percaya (Bandung: Kalam Hidup, 1976), 39.

${ }^{25}$ Tomatala, Penginjilan Masa Kini, 215.
} 
mencakup upaya pemahaman akar penyebab keprihatinan sosial sekaligus mengembangkan prakarsa pemberdayaan masyarakat untuk memenuhi kebutuhan hidup yang layak. Hanya dengan pemahaman pelayanan diakonia sedemikian gereja dapat berfungsi sebagai agen transformasi di tengah masyarakat sebagai pewujudan karya keselamatan terang dunia.

Jadi yang dmaksud dengan pemberitaan Injil aspek diakonia adalah: Pertama, mewujudkan keadilan Allah bagi manusia dalam bidang social, dan kedua, menyampaikan keselamatan dari Allah dalam Tuhan Yesus Kristus melalui pemberdayaan masyarakat.

\section{Metode Penelitian}

Penelitian ini bersifat korelasional. Penelitian korelasi atau korelasional adalah suatu penelitian untuk mengetahui hubungan dan tingkat hubungan antara dua variabel atau lebih tanpa ada upaya untuk mempengaruhi variabel tersebut sehingga tidak terdapat manipulasi variabel. ${ }^{26}$ Populasi penelitian ini adalah para guru-guru yang beragama Kristen di sekolah-sekolah Yayasan Pendidikan Kristen Pelita Pengharapan Kabupaten Cilacap. Jumlah populasi guru-guru Kristen di di sekolah sebanyak 52 orang yang tersebar di 9 sekolah yang ada di YPK Pelita Pengharapan. Pengumpulan data dilaksanakan pada tanggal 19 Agustus 2013 sampai dengan 23 Agustus 2013. Dalam penelitian ini, alat pengumpulan data yang digunakan adalah kuesioner. Skala yang digunakan adalah skala likert dengan skor jawaban $5=$ Sangat setuju, $4=$ Setuju, 3 = Ragu-ragu, 2 = Tidak setuju dan $1=$ Sangat tidak setuju.

Variabel penelitian yang digunakan dalam adalah panggilan guru Kristen sebagai variabel bebas $(\mathrm{X})$ dan pemberitaan Injil guru-guru GKJ sebagai variabel terikat (Y). Ada satu batasan operasional untuk variabel $\mathrm{X}$ dan empat batasan operasional untuk variabel Y, yaitu:

1. Variabel bebas (X) panggilan guru Kristen memiliki indikator :
a. Meneladani Kristus.
b. Mengasihi para murid.
c. Bertumbuh di dalam Kristus.
d. Bergantung pada Kuasa Roh Kudus.
e. Memberikan sentuhan Firman Tuhan.
f. Membawa kepada perjumpaan dengan Kristus.

2. Variabel terikat (Y) pemberitaan Injil Guru-guru GKJ memiliki indikator :
a. Motivasi Pemberitaan Injil.
b. Pemberitaan Injil aspek koinonia.
c. Pemberitaan Injil aspek marturia.
d. Pemberitaan Injil aspek diakonia.

\footnotetext{
${ }^{26}$ Purwanto. Metode Penelitian Kuantitatif: Untuk Psikologi dan Pendidikan (Yogyakarta: Pustaka Belajar, 2010), 24.
} 
Dalam penelitian ini, digunakan beberapa model analisis data yaitu: analisis Regresi Linear Sederhana Analisis Regresi Linear sederhana digunakan untuk memperkirakan pengaruh variabel bebas $(\mathrm{X})$ terhadap variabel terikat $(\mathrm{Y})$.

\section{Hasil Dan Pembahasan}

Berdasarkan pada hasil analisis hubungan dua variabel diperoleh koefisien korelasi yang disimbolkan dengan $r$ sebesar 0,937 , seperti ditunjukkan pada tabel di bawah ini:

\section{Tabel 1: Hasil Uji R}

Model Summary

\begin{tabular}{|c|c|c|c|c|}
\hline Model & $\mathrm{R}$ & R Square & $\begin{array}{c}\text { Adjusted R } \\
\text { Square }\end{array}$ & $\begin{array}{c}\text { Std. Error of } \\
\text { the Estimate }\end{array}$ \\
\hline 1 & $.937^{\mathrm{a}}$ & .878 & .875 & 2.988 \\
\hline
\end{tabular}

a. Predictors: (Constant), $\mathrm{X}$

Hal ini menunjukkan keeratan hubungan antara pemahaman panggilan guru Kristen dengan pemberitaan Injil guru-guru Gereja Kristen Jawa berada pada level yang sangat tinggi, bahkan mendekati sangat tinggi, yaitu antara 0,800 - 1,000. $\mathrm{R}$ square adalah koefisien determinasi atau koefisien penentu. Nilai $\mathrm{R}$ square terletak di antara angka 0 dan 1. R square didapat dari menghitung $\mathrm{r}^{2}$. Apabila semakin nilai $\mathrm{R}$ square mendekati 1 maka semakin besar pengaruh variabel bebas terhadap variabel terikat. Nilai $\mathrm{R}$ square untuk penelitian ini adalah 0,878, yang berarti pemahaman panggilan guru Kristen dapat menjelaskan pemberitaan Injil guru-guru Gereja Kristen Jawa sebesar 0,878 \%.

Tabel 2: Hasil Uji Regresi

\begin{tabular}{|c|c|c|c|c|c|c|}
\hline \multicolumn{7}{|c|}{ Coefficients $^{\mathrm{a}}$} \\
\hline & & \multicolumn{2}{|c|}{ Unstandardized Coefficients } & \multirow{2}{*}{$\begin{array}{c}\begin{array}{c}\text { Standardized } \\
\text { Coefficients }\end{array} \\
\text { Beta }\end{array}$} & \multirow[b]{2}{*}{$\mathrm{T}$} & \multirow[b]{2}{*}{ Sig. } \\
\hline \multicolumn{2}{|c|}{ Model } & B & Std. Error & & & \\
\hline \multirow[t]{2}{*}{1} & (Constant) & 9.580 & 4.190 & & 2.286 & .027 \\
\hline & $\mathrm{X}$ & .907 & .048 & .937 & 18.738 & .000 \\
\hline \multicolumn{3}{|c|}{ a. Dependent Variable: Y } & & & & \\
\hline
\end{tabular}

Berdasarkan pada tabel 2 di atas diperoleh nilai a sebesar 9,580 yang berarti tanpa pemahaman panggilan guru Kristen atau nilai pemahaman panggilan guru Kristen sebesar 0, pemberitaan Injil guru-guru Gereja Kristen Jawa mencapai 9,580. Besarnya pengaruh variabel $\mathrm{X}$ terhadap variabel $\mathrm{Y}$ dapat dilihat dari besarnya koefisien regresi atau b yaitu sebesar 0,907. Hal ini menunjukkan setiap kenaikan satu angka pada pemahaman panggilan guru Kristen berpengaruh positif atau menaikkan nilai pemberitaan Injil guru-guru Gereja Kristen Jawa sebesar 90,7. Hasil uji regresi juga 
menunjukkan bahwa diperoleh nilai sig. sebesar 0,000. Angka ini lebih kecil dari taraf signifikansi sebesar 0,005, sehingga pemahaman panggilan guru Kristen berepngaruh signifikan terhadap pemberitaan Injil guru-guru Gereja Kristen Jawa.

Seberapa besar pemahaman panggilan guru Kristen bagi guru-guru Gereja Kristen Jawa di Sekolah Yayasan Pendidikan Kristen Pelita Pengharapan dapat dilihat hasil pengolahan data sebagai berikut :

Tabel 3: Kategori PemahamanTentang Panggilan Guru Kristen

\begin{tabular}{|c|c|c|}
\hline Interval & Kategori & Nilai Lower dan Upper Bound Variabel X \\
\hline $57-72$ & Rendah & \\
\hline $73-88$ & Sedang & $83,70-88,61$ (Sedang) \\
\hline $89-104$ & Tinggi & \\
\hline
\end{tabular}

Berdasarkan pada analisis data yang dilakukan dengan menggunakan confidence interval sebesar 5\%, diperoleh angka Lower Bound dan angka Upper Bound antara 83,70 - 88,61. Berdasarkan pada temuan tersebut di atas dapat disimpulkan bahwa pemahaman panggilan guru Kristen berada pada kategori "Sedang".

Adapun tabel kategori dan posisi pemberitaan Injil guru-guru Gereja Kristen Jawa seperti berikut:

Tabel 4: Kategori Pemberitaan Injil Guru-guru Gereja Kristen Jawa

\begin{tabular}{|c|c|c|}
\hline Interval & Kategori & Nilai Lower dan Upper Bound Variabel Y \\
\hline $63-75$ & Rendah & \\
\hline $76-88$ & Sedang & \multirow{2}{*}{$85,33-90,08$ (Sedang menuju tinggi) } \\
\hline $89-101$ & Tinggi & \\
\hline
\end{tabular}

Berdasarkan pada analisis data yang dilakukan dengan menggunakan confidence interval sebesar 5\%, diperoleh angka Lower Bound dan angka Upper Bound antara 85,33 - 90,08. Berdasarkan pada temuan tersebut di atas dapat disimpulkan bahwa guru-guru Kristen Gereja Kristen Jawa sebagai Pemberita Injil berada pada kategori "Sedang menuju tinggi".

\section{Kesimpulan}

Hasil analisis pengaruh pemahaman tentang panggilan guru Kristen terhadap pemberitaan Injil guru-guru Gereja Kristen Jawa di sekolah-sekolah Yayasan Pendidikan Kristen Pelita Pengharapan Kabupaten Cilacap menunjukkan bahwa terdapat pengaruh yang positif dan signifikan pemahaman panggilan guru Kristen terhadap pemberitaan Injil guru-guru Kristen di sekolah-sekolah Yayasan Pendidikan Kristen Pelita Pengharapan. Semakin tinggi pemahaman panggilan guru Kristen semakin tinggi pemberitaan Injil guru-guru Kristen di sekolah-sekolah Yayasan Pendidikan Kristen Pelita Pengharapan. Hasil penelitian menunjukkan pemahaman panggilan guru Kristen memberikan pengaruh yang sangat besar terhadap peningkatan 
pemberitaan Injil guru-guru Gereja Kristen Jawa di sekolah-sekolah Yayasan Pendidikan Kristen Pelita Pengharapan. Semakin tinggi tingkat pemahaman panggilan sebagai guru Kristen, maka akan meningkat pula pemberitaan Injil yang dilakukannya.

Hasil penelitian juga menunjukkan adanya kecenderungan pemahaman tentang panggilan guru Kristen di sekolah-sekolah Yayasan Pendidikan Kristen Pelita Pengharapan Kabupaten Cilacap berada pada kategori "Sedang". Hasil penelitian juga menunjukkan adanya kecenderungan guru-guru Kristen sebagai Pemberita Injil di sekolah-sekolah Yayasan Pendidikan Kristen Pelita Pengharapan Kabupaten Cilacap berada pada "Sedang menuju tinggi".

\section{Rekomendasi}

Berdasarkan pada kesimpulan hasil penelitian, maka diusulkan saran-saran sebagai berikut :

Pertama, guru-guru Kristen di sekolah-sekolah Yayasan Pendidikan Kristen Pelita Pengharapan perlu meningkatkan pemahaman panggilannya sebagai guru Kristen sebagai salah upaya agar pemberitaan Injil di sekolah semakin meningkat.

Kedua, para guru memiliki peranan yang sangat penting untuk memberikan warna Kristiani yang dimasukkan dalam setiap pelajaran yang diampu sehingga mampu meningkatkan pemberitaan Injil.

Ketiga, proses penerimaan guru-guru di sekolah-sekolah Yayasan Pendidikan Kristen Pelita Pengharapan disarankan juga memperhatikan aspek keterpanggilan sebagai guru dan sekaligus sebagai orang Kristen yang rindu melayani Tuhan Yesus Kristus di bidang pendidikan.

Keempat, perlunya pihak pengurus Yayasan Pendidikan Kristen Pelita Pengharapan yang menaungi sekolah-sekolah beserta dengan kepala sekolah melakukan pembinaan untuk meningkatkan pemahaman panggilan sebagai seorang guru Kristen, agar pemahaman dan pelaksanaan pemberitaan Injil oleh guru-guru dapat ditingkatkan.

Kelima, dalam pelaksanaan pembinaan tentang pemahaman panggilan guru Kristen juga diperlukan penekanan yang terkait dengan pemberitaan Injil aspek marturia proklamasi agar supaya seimbang dengan pemberitaan Injil presensi dan persuasi.

Keenam, Dewan Pembina Yayasan Pendidikan Kristen Pelita Pengharapan yang merupakan representasi Gereja-gereja Kristen Jawa di Klasis Citanduy selalu mendorong dan mendukung dalam hal pendanaan serta sumber daya manusia untuk mengadakan pembinaan, pelatihan, mentoring, supervisi dan evaluasi berkala untuk meningkatkan pemahaman panggilan guru Kristen yang akan membawa dampak pada pemberitaan Injil di sekolah-sekolah Yayasan Pendidikan Kristen Pelita Pengharapan.

\section{Referensi}

Abineno, J.L. Ch. Sekitar Diakonia Gereja. Jakarta : BPK Gunung Mulia, 1976. Abriwijono, Dwi Eko. Studi Evaluasi Motivasi Mengajar Guru di Sekolah Kristen YPK Pelita Pengharapan (Tesis). Semarang : STBI, 2010. . Sejarah Klasis Citanduy. Sidareja : Klasis Citanduy, 2007. 
Cook, Robert. Setelah Aku Percaya. Bandung : Kalam Hidup, 1976.

Enklaar, I.H dan E.G. Homrighausen. Pendidikan Agama Kristen. Jakarta : BPK Gunung Mulia, 1991.

GKJ, Sinode. Sejarah Singkat Sinode GKJ. Salatiga : Sinode GKJ,2013. . Pokok-pokok Ajaran Gereja Kristen Jawa. Salatiga : Sinode GKJ, 2005. Tata Gereja. Salatiga : Sinode GKJ, 2005.

Hawthorne, Stephen. Perspektif Penginjilan Sedunia. tp:tt.

Lembaga Alkitab Indonesia. Alkitab. Jakarta: Lembaga Alkitab Indonesia, 1974.

Lickona Thomas, Pendidikan Karakter, Panduan Lengkap Mendidik Siswa Menjadi Pintar dan Baik. Bandung : Nusamedia, 2013.

Nuhamara, Daniel. Pembimbing Pendidikan Agama Kristen. Bandung : Jurnal Info Media, 2007.

Nainggolan, John M. Menjadi Guru Agama Kristen; Suatu Upaya Peningkatan Mutu dan Kualitas Profesis Keguruan. Bandung: Generasi Info Media, 2007.

Pazmino, Robert W. Foundational Issues in Christian Education: An Introduction in Evangelical Perspective. (http://icctejournal.org/issues/v4i1/v4i1-book-review/)

Purwanta, Iswara Rintis. Prapenginjilan. Yogyakarta : Penerbit ANDI, 2012.

Purwanto. Metode Penelitian Kuantitatif : untuk Psikologi dan Pendidikan. Yogyakarta: Pustaka Belajar, 2010.

Posumah, Jedida T-Santosa. "Pendidikan Agama Kristen di Sekolah : Suatu Bidang Studi atau Asuhan Iman Kristen?" dalam Ajarlah Mereka Melakukan. Jakarta : BPK Gunung Mulia, 1998.

Sukoco, Lukas Eko. Panduan Pelayanan Gerejawi. Yogyakarta : Taman Pustaka Kristen, 2006.

Sopater, Sularso. "Memantapkan Pelaksanaan Identitas dan Ciri Khas Pendidikan Kristen Secara Kontinyu dan Konsisten" dalam buku Identitas dan Ciri Khas Pendidikan Kristen di Indonesia. Jakarta : BPK Gunung Mulia. 2006.

Tomatala, Yakob. Teologi Misi. Jakarta : Leadership Foundation, 2003. . Penginjilan Masa Kini. Malang : Gandum Mas, 2004.

Wagner, C. Peter. Strategi Perkembangan Gereja. Malang : Gandum Mas, th. Wiyono, Andreas Untung. Eklesiologi GKJ. Salatiga: Sinode GKJ, 2013. 